\title{
MOLECULAR EVOLUTION INFERRED FROM SMALL SUBUNIT RRNA SEQUENCES: WHAT DOES IT TELL US ABOUT PHYLOGENETIC RELATIONSHIPS AND TAXONOMY OF THE PARABASALIDS?
}

\author{
VISCOGLIOSI E.*, EDGCOMB V.P.**, GERBOD D.**, NOËL C.* \& DELGADO-VISCOGLIOSI P.***
}

\section{Summary :}

The Parabasala are a primitive group of protists divided into two classes: the trichomonads and the hypermastigids. Until recently, phylogeny and taxonomy of parabasalids were mainly based on the comparative analysis of morphological characters primarily linked to the development of their cytoskeleton. Recent use of molecular markers, such as small subunit (SSU) rRNA has led to new insights into the systematics of the Parabasala and other groups of protists. An updated phylogeny based on SSU rRNA is provided and compared to that inferred from ultrastructural data. The SSU rRNA phylogeny contradicts the dogma equating simple characters with primitive characters. Hypermastigids, possessing a hyperdeveloped cytoskeleton, exhibit the most basal emergence in the parabasalid lineage. Other observations emerge from the SSU rRNA analysis, such as the secondary loss of some cytoskeleton structures in all representatives of the Monocercomonadidae, the existence of secondarily free-living taxa (reversibility of parasitism) and the evidence against the co-evolution of the endobiotic parabasalids and their animal hosts. According to phylogenies based on SSU rRNA, all the trichomonad families are not monophyletic groups, putting into question the validity of current taxonomic assignments. The precise branching order of some taxa remains unclear, but this issue can possibly be addressed by the molecular analysis of additional parabasalids. The goal of such additional analyses would be to propose, in a near future, a revision of the taxonomy of this group of protists that takes into account both molecular and morphological data.

KEY WORDS : Parabasalids, trichomonads, small subunit rRNA, molecula phylogeny, evolution, taxonomy.
Résumé : ÉVOLUTION MOLÉCULAIRE BASÉE SUR LES SÉQUENCES DE L'ARNR DE LA PETTTE SOUS-UNITÉ : QUE NOUS PROPOSE-T-ELLE SUR LES

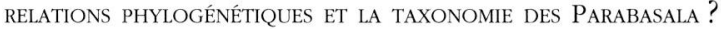

Les Parabasala forment un groupe de protistes primitifs regroupant deux classes: les trichomonadines et les hypermastigines. Jusqu'à ces dernières années, les relations de parenté et la taxonomie des Parabasala étaient essentiellement basées sur l'analyse comparative des caractères morphologiques qui étaient principalement liés au développement de leur cytosquelette. L'utilisation récente d'indicateurs moléculaires comme l'ARN ribosomique de la petite sous-unité a largement modifié la systématique des Parabasala comme celle d'autres groupes de protistes. Un arbre basé sur les séquences des ARN ribosomiques de la petite sous-unité est proposé et comparé à celui établi d'après les données ultrastructurales. Cet arbre contredit le dogme qui était qu'un caractère dit simple ne pouvait être qu'un caractère primitif. En effet, les hypermastigines, dotées d'un cyłosquelette très développé, ont l'émergence la plus précoce dans la lignée des Parabasala. D'autres observations peuvent être tirées de cet arbre comme la perte secondaire de certaines structures cytosquelettiques chez tous les représentants de la famille des Monocercomonadidae, l'existence de formes secondairement libres (réversibilité du parasitisme) et l'absence de co-évolution entre les Parabasala et leurs hôtes respectifs. II remet aussi en cause la validité de la taxonomie actuelle puisque toutes les familles de trichomonadines ne forment pas de groupes monophylétiques. L'émergence précise de certains taxa reste encore indécise mais ceci devrait pouvoir être résolu par l'étude moléculaire de plusieurs espèces de Parabasala encore non étudiées. La finalité de ce travail serait de proposer, dans un avenir proche, une nouvelle taxonomie de ce groupe de protistes qui prendrait en compte à la fois les données moléculaires et les données morphologiques.

MOTS CLÉS : Parabasala, trichomonadines, ARNr de la petite sous-unité, phylogénie moléculaire, évolution, taxonomie.

gerolle, 1976; Honigberg \& Brugerolle, 1990). They are distinguished by the presence of one or more parabasal apparatus comprising a parabasal body (Golgi complex) and a parabasal filament. It is from this structural attribute that the name of the superorder (Parabasalidea) derives. These organisms are anaerobic, lack mitochondria, but possess hydrogenosomes, specialised organelles lacking nucleic acids and surrounded by a double membrane in which anaerobic metabolism takes place. All parabasalid genera studied to date exhibit a special type of closed mitosis called cryptopleuromitosis, characterized by the persistence of the nuclear envelope and the presence of an extranuclear spindle (Brugerolle, 1975a). These structural

\footnotetext{
* Laboratoire de Biologie Comparée des Protistes, UPRESA CNRS 6023 , Avenue des Landais, Aubière, France.

** Josephine Bay Paul Center for Molecular Evolution, Marine Biological Laboratory, Woods Hole, MA 02543, USA.

${ }^{* * *}$ Laboratoire d'Oncologie Moléculaire, Centre Jean Perrin, Rue Montalembert, Clermont-Ferrand, France.

Correspondence: Dr Eric Viscogliosi.

Tel: (33) 473407472 - Fax: (33) 473407670

E-mail: viscogliosi@cicsun.univ-bpclermont.fr
} 
characteristics allow the separation of the well defined superorder Parabasalidea from other flagellated lineages.

More than eighty parabasalid genera have been identified to date, and classified into two orders: Trichomonadida and Hypermastigida (Corliss, 1984; CavalierSmith, 1993). Most trichomonads are found in association with the respiratory, digestive and reproductive systems of vertebrates, including mammals and invertebrates. There are only three species of trichomonads that infect humans, and they are extremely site-specific (Honigberg, 1978). Trichomonas tenax lives in the oral cavity, Pentatrichomonas hominis in the intestinal tract and Trichomonas vaginalis in the genitourinary tract. Only Trichomonas vaginalis is considered pathogenic (Graves \& Gardner, 1993). This parasite is the causative agent of human trichomoniasis which has emerged as the most prevalent nonviral sexually transmitted disease worldwide in recent years. The "classic signs" of trichomoniasis are vaginitis and exocervicitis but Trichomonas vaginalis has also been implicated in the pathogenesis of preterm labor, premature rupture of membranes, upper reproductive tract postsurgical infections (Heine \& McGregor, 1993), and may have an important role in the amplification of HIV-1 transmission in developing countries (Sorvillo \& Kerndt, 1998). Considerable research has also been done on the trichomonads that infect animals of economic importance to humans, such as Tritrichomonas foetus (Yule et al., 1989). It is the causative agent of bovine trichomoniasis, colonizing both male and female reproductive tracts. The infection in cows is serious and usually leads to infertility, abortion and pyometra, resulting in substantial economic losses. Some trichomonad species are also known to be free-living and have been isolated from the sediments of freshwater lakes (Farmer, 1993) and marine sediments (Edgcomb et al., 1998).

Species belonging to the second class of parabasalids, the hypermastigids, are found in association with the digestive tracts of some insects (Yamin, 1979). The insect hosts are termites and wood-eating cockroaches that maintain complex symbiotic communities of bacteria and protists in their hindguts. These symbiotic hypermastigids have a possible role in the digestion of wood components and are required for the survival of their wood-feeding hosts (Grosovsky \& Margulis, 1982; Breznak, 1982). It is difficult to extricate and study hypermastigids from this intimate community that are refractory to culturing methodologies and hence, most molecular work.

Until recently, phylogenetic relationships among parabasalids were mainly examined by the comparative analysis of morphological characters. In 1963, Honigberg was the first to publish his view of the evolutio- nary relationships among the trichomonads. This scheme was based on light-microscope studies of living, or fixed and stained material. Thereafter, numerous electron microscope studies provided information confirming the original scheme of Honigberg (Brugerolle, 1976). Common features shared between hypermastigids and trichomonads led to the formal union of these two classes of protists into the parabasalids (Levine et al., 1980). These evolutionary schemes were mainly based on a restricted number of characters mostly linked to the structure and development of the cytoskeleton. As with other protist groups, the presumed evolution of the parabasalids reflected the traditional view regarding polarization of cytoskeletal developement from simple to complex. Parabasalids exhibiting a rudimentary cytoskeleton were thought to occupy a basal position and to have given rise to the other more complex parabasalids. Despite the well known morphological characteristics of most parabasalid taxa, their phylogenetic relationships were often unclear. Indeed, identifying homologous morphological features and defining polarity of character states is extremely difficult and frequently arbitrary. The absence of a character can either be ancestral or due to secondary loss, indistinguishable outcomes by morphological analyses alone. Phylogenies based on molecular analyses provided new insights into the reconstruction of evolutionary relationships in parabasalids, as well as other protist groups.

Zuckerkandl \& Pauling (1965) were the first to propose the use of the gene sequences of macromolecules as molecular indicators. Not all molecules are equally useful for such studies and the molecule of choice has been the small subunit rRNA (SSU rRNA). This molecule is conserved throughout the living world (present in all known species as well as in mitochondria and chloroplasts), providing thousands of homologous characters, thus allowing in principle the construction of phylogenies for any chosen group (Pace et al., 1986; Woese, 1987; Olsen \& Woese, 1993). Furthermore, SSU rRNA proved to be an almost ideal phylogenetic marker given its functional conservation, the size of the molecule, and its primary and secondary structures which contain regions of variable conservation, thus aiding the alignment of sequences between species and allowing the comparison of both closely- and distantlyrelated organisms. Sequencing techniques have been subsequently streamlined, and several hundred SSU rRNA sequences from eucaryotes are now available in public databases. The use of PCR primers targeting conserved regions of the genes encoding SSU rRNAs have made possible the cloning and sequencing of unculturable species, such as many of the parabasalid taxa (Medlin et al., 1988). In sum, SSU rRNA appeared to be the best tool available for determination of relationships among the parabasalids. 
In this study, we analyze a broad phylogeny including SSU rRNA sequences from more than 25 parabasalid species to compare morphological and molecular phylogenies of parabasalids. We note large discrepancies between ultrastructural and molecular data, and therefore propose changes in the presumed phylogenetic relationships of parabasalids and question the present validity of taxonomic assignments in this group of protists. In addition, we put forward hypotheses on the evolution of the cytoskeleton of these microorganisms.

\section{CYTOSKELETON}

\section{OF THE TRICHOMONAD CELL}

Whe basic structure of a trichomonad cell is illustrated by Figure 1 (Brugerolle, 1976; Honigberg \& Brugerolle, 1990). Trichomonads are equipped with three to five anteriorly-directed flagella. In the hypermastigids, the number of anterior flagella multiplied, reaching as many as a thousand. In trichomo-

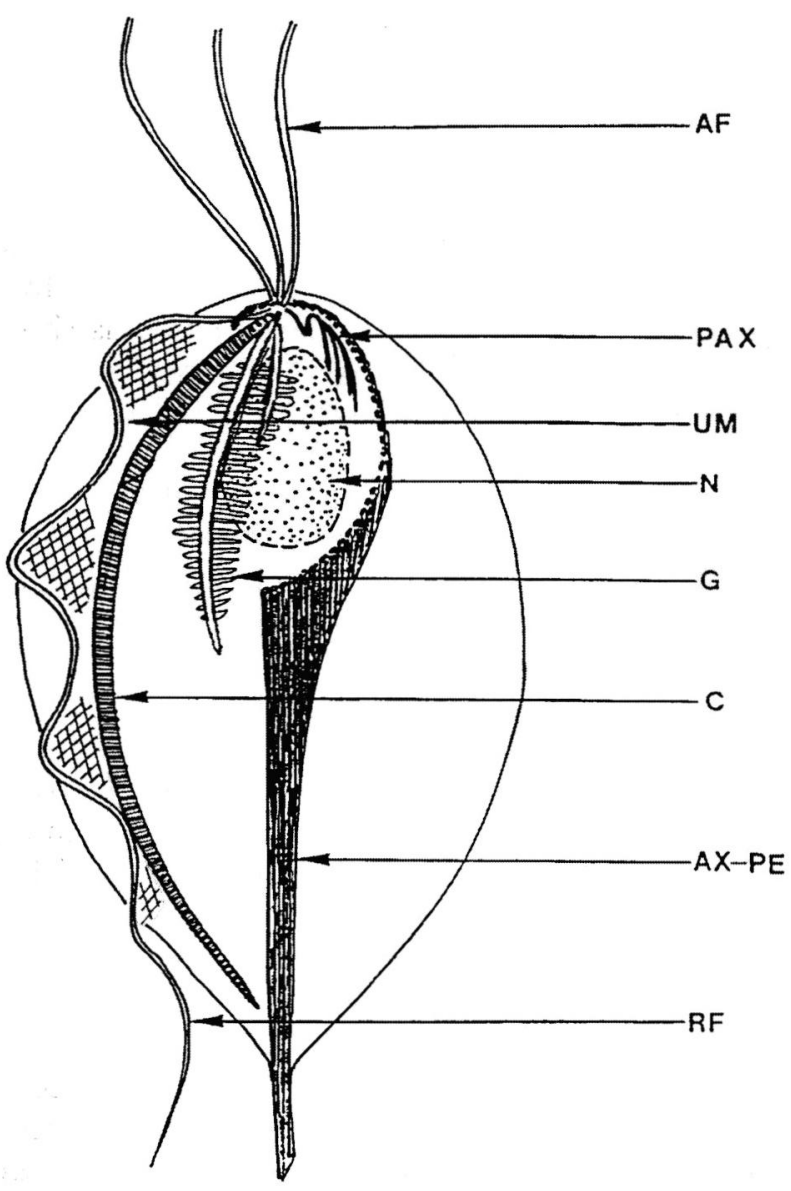

Fig. 1. - Schematic diagram of a trichomonad cell. AF: anterior flagella; PAX: preaxostylar fibers; UM: undulating membrane; $\mathrm{N}$ : nucleus; G: parabasal apparatus (parabasal fibers plus dictyosomes); C: costa; AX-PE: axostyle-pelta complex; RF: recurrent flagellum.

\section{Annexe I. - Glossary}

Apomorphy: A derived character state.

Bootstrapping: A statistical method based on repeated random sampling (up to 1,000 and more) with replacement from an original sample to provide a collection of new estimates of some parameter, from which confidence limits can be calculated (percentages).

Clade: A monophyletic taxon.

Monophyletic: A group that contains all of the descendants of the most recent common ancestor of the constituent species.

Outgroup: One or more taxa assumed to be outside the group under consideration (ingroup) and used to help resolve the polarity of characters.

Plesiomorphy: An ancestral character state.

Polyphyletic: Term applied to a group of organisms which does not include the most recent common ancestor of those organisms.

Taxon: Any named group of organisms, not neccessarily a clade.

nads, the recurrent flagellum is either free or attached to the cell body, forming the undulating membrane. The undulating membrane is composed of the recurrent flagellum and microfibrillar structures located below the membrane of the cell along the adherent zone with the recurrent flagellum. The flagella and undulating membrane are the locomotive organelles. The principal mean of locomotion in trichomonad genera is the undulating membrane, whereas the anterior flagella mainly serve to change the direction of movement (Kulda et al., 1986). A broad striated root, the costa, occurs only in trichomonads possessing an undulating membrane. It is assumed that the costa serves as a mechanical support for the undulating membrane. Indeed, the costa extends immediately below it within the cytoplasm and in some taxa, microfibrillar layers connect the costa to the undulating membrane.

Several characters are common to all parabasalid species. The first one is the striated root known as the parabasal fiber, which polarizes the dictyosomes forming the parabasal apparatus. The parabasal apparatus is unique to the parabasalids. There is no such described relation between a striated root and the dictyosomes in other groups of protists (Grain, 1986). In most of the trichomonads, the root is composed of two branches or parabasal fibers and each branch may support a Golgi body. In larger cells such as hypermastigids, there are up to 50 parabasal fibers, each supporting a Golgi body (Hollande \& Caruette-Valentin, 1971). Another common cytoskeletal structure is the microtubular axostyle-pelta complex composed of a 
sheet of cross-linked microtubules. It constitutes the longitudinal axis of the cell. In some genera the axostyle-pelta complex is composed of rolls of microtubular rows giving a very broad structure. The preaxostylar fibers are additional striated roots shared by all parabasalids. They are connected to the basal bodies and adhere to the axostyle-pelta complex. Previous observations have shown that microtubules of the axostyle-pelta complex begin to assemble in the vicinity of the preaxostylar fibers, which seem to function as a microtubule organizing center (Brugerolle, 1976).

\section{TAXONOMY OF THE PARABASALIDS}

A s stated above, parabasalids exhibit diverse cytoskeletal arrangements, composed of microfibrillar and microtubular structures. Some of these structures are common to all the parabasalid taxa while others are genera- or family-specific and, thus, represent significant taxonomic features. On the basis of cytological studies, the trichomonads were separated into five families (Honigberg, 1963; Brugerolle, 1976; Lee, 1985; Pecka et al., 1996): Monocercomonadidae, Trichomonadidae, Cochlosomatidae (only one genus recently identified (Pecka et al., 1996), Cocblosoma and thus not indicated in Figure 2), Devescovinidae and Calonymphidae (Fig. 2). The Monocercomonadidae have a rudimentary cytoskeleton. They do not have a costa, and if present, have a weakly developed undulating membrane. In the proposed phylogenetic trees of Honigberg (1963) and Brugerolle (1976), the Monocercomonadidae occupied a basal position and gave rise to the Trichomonadidae exhibiting a more complex cytoskeleton. Trichomonadidae, which possess a costa and an undulating membrane, are divided into two main subfamilies: the Trichomonadinae and the Tritrichomonadinae, depending in large measure on the types of costa and undulating membrane (Brugerolle, 1976). Two major costa types can be distinguished based on band pattern, although each type exhibits the same periodicity (about $42 \mathrm{~nm}$ ). The first type (C1-type) is present in Tritrichomonas foetus and other Tritrichomonadinae, and the second one (C-type) is found in Trichomonas vaginalis and other Trichomonadinae. Tritrichomonadinae also possess a "rail-like" undulating membrane while Trichomonadinae exhibit a "lamellar" one.

Devescovinidae, Calonymphidae and hypermastigids probably evolved from Tritrichomonadinae (Brugerolle, 1976). In Devescovinidae there is a specialized organelle that may be homologous with the undulating membrane of Trichomonadidae. The recurrent flagellum adheres to the plasma membrane of the cell, under which there is a complex system of fibers called

the cresta by Kirby (1941). The last trichomonad family, the Calonymphidae, is characterized by the multiplication of nuclei and of their associated mastigont systems. Finally certain characters have undergone an exaggerated development in hypermastigids, such as the multiplication of flagella and parabasal fibers.

\section{EARLY EMERGENCE OF THE PARABASALIDS AMONG THE EUKARYOTES}

A t the end of the 1970's, Taylor proposed phylogenetic relationships among eukaryotes on data allow the identification of numerous groups of protists including the parabasalids, but fail to generate a phylogenetic framework linking these groups. In a detailed cytological study of parabasalids, Brugerolle (1976) did not identify possible relationships with other groups of flagellated protists. The phenotypic variation within protists far exceeds that seen in other eukaryotic kingdoms, making the identification of homologous morphological characters on a large evolutionary scale, such as that encompassing all protists, difficult. As an alternative to traditional phenotypic markers, phylogenetic relationships can be established through comparisons of SSU rRNAs. Sequence analyses have revealed the existence of three primary lines of descent: Eubacteria (or Bacteria), Archaebacteria (or Archaea) and Eukaryota (Pace et al., 1986). A phylogram, including most of the protist groups, is shown in Figure 3 (Sogin, 1991). Diplomonads, such as Giardia lamblia, represent the earliest diverging lineage, followed by the microsporidia and parabasalids. Several studies (Leipe et al., 1993; Van Keulen et al., 1993; Philippe \& Adoutte, 1995) have shown that the relative branching order of these three amitochondriate protist groups is unsettled. Indeed the order of emergence of diplomonads, microsporidia and parabasalids at the base of the eukaryotic tree may be significantly influenced by outlying prokaryotic taxa with different $\mathrm{G}+\mathrm{C}$ compositions in their rRNA coding regions. Their "primitive" position could also be consistent with the lack of mitochondria, suggesting that mitochondrial endosymbiosis did not occur at the origin of the first eukaryotic cell (Cavalier-Smith, 1993). However, recent molecular phylogenies based primarily on heat shock proteins suggest that the mitochondrial endosymbiotic event could have occurred before the emergence of diplomonads (Roger et al., 1998), microsporidia (Hirt et al., 1997; Germot et al., 1997; Peyretaillade et al., 1998) and parabasalids (Bui et al., 1996; Germot et al., 1996; Roger et al., 1996) indicating that these groups may be secondarily amitochondriate. In this case, if we consider that the eukaryotic cell originated before the 


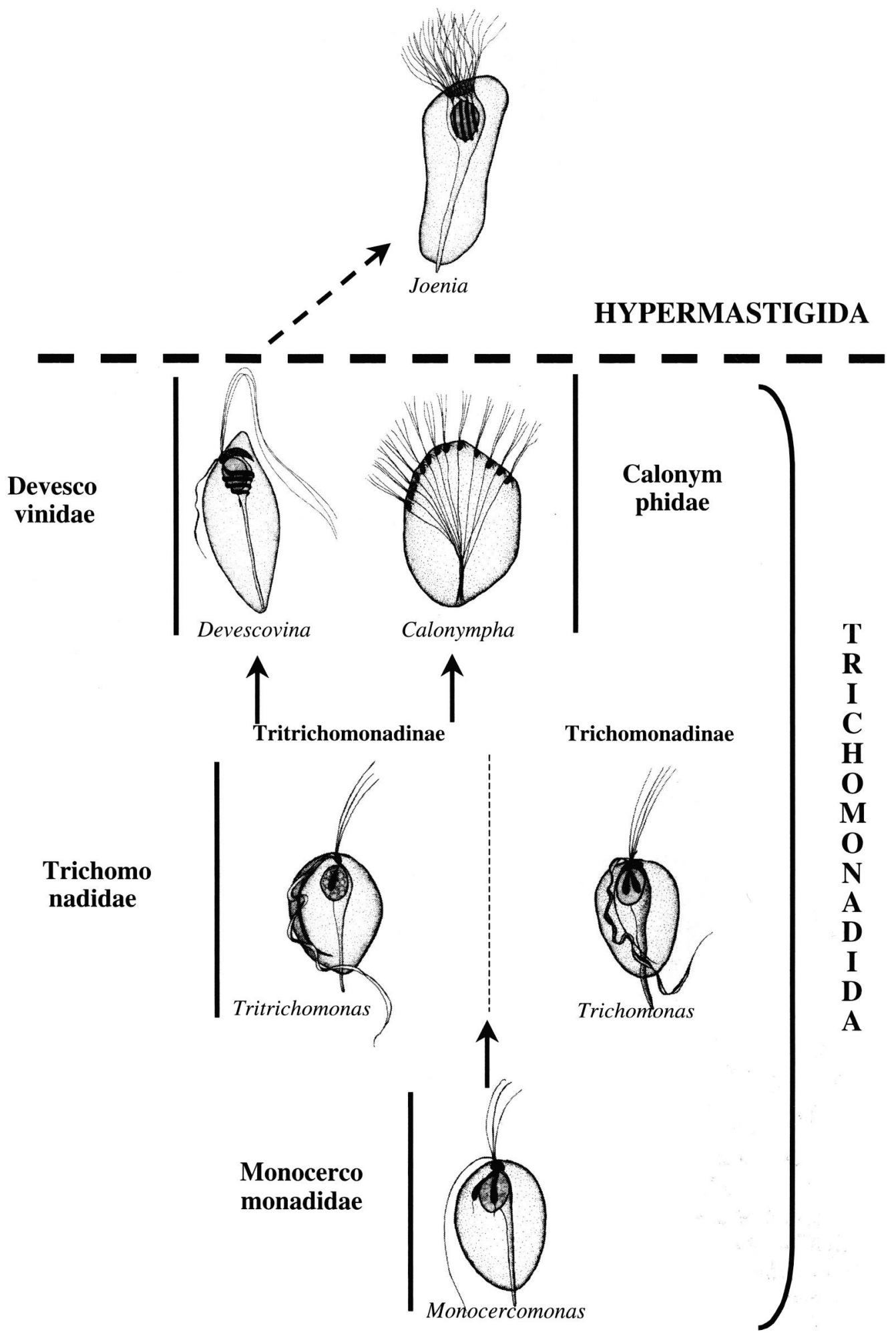

Fig. 2. - Diagrammatic representation of the presumed evolution in parabasalids established from morphological data (redrawn from Honigberg, 1963 and Brugerolle, 1976; modified from Dyer, 1989). 


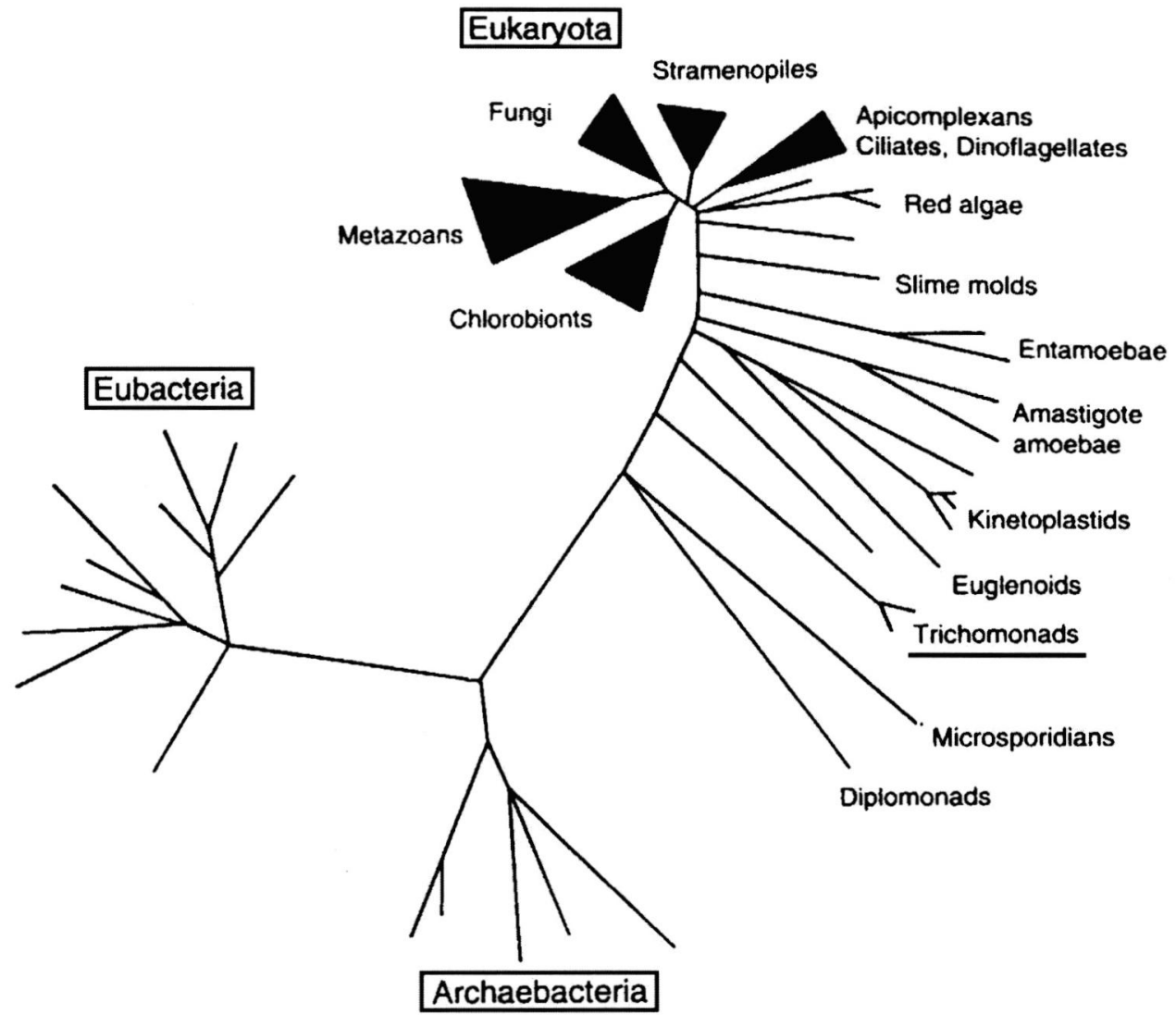

Fig. 3. - Three kingdom unrooted tree inferred from the comparison of SSU rRNA sequences. Lengths of branches correspond to genetic distances. The earliest diverging eukaryotic lineages are presented by amitochondriate protists: Diplomonads, Microsporidia and Trichomonads Trichomonads are underlined (modified from Sogin, 1991).

acquisition of the mitochondrion endosymbiont, thus there may be primitively amitochondriate eukaryotes remaining to be discovered.

\section{MOLECULAR PHYLOGENIES OF PARABASALIDS}

T the first molecular phylogeny of parabasalids was based on large subunit rRNA sequences (LSU rRNA) and was limited to the comparison of several domains of the molecule from nine trichomonad species (Viscogliosi et al., 1993). More recently, other molecules have been used as phylogenetic indicators, such as iron-containing superoxide dismutase (FeSOD) and glyceraldehyde-3-phosphate dehydrogenase $(\mathrm{GAPDH})$ in order to infer relationships within almost the same sampling of trichomonad taxa (Viscogliosi et al., 1996, 1998). These molecular trees only included representatives of the Monocercomonadidae and Trichomonadidae because of the unavailability of axenic cultures of representatives of the other high level taxa. This restriction has been circumvented by the use of specific primers allowing the amplification of SSU rRNA coding regions from selected eukaryotes.
The sequences of these primers are conserved in parabasalids and can be used to amplify species which are difficult to culture (Medlin et al., 1988). Gunderson et al. (1995) were the first to publish a large phylogeny of parabasalids inferred from SSU rRNA sequences obtained from four Trichomonadida families. Several authors subsequently obtained additional sequences from trichomonads (Berchtold \& König, 1995; Berchtold et al., 1995; Silberman et al., 1996; Fukura et al., 1996; Edgcomb et al., 1998; Keeling et al., 1998; Delgado-Viscogliosi et al., 1999) and hypermastigids (Keeling et al., 1998; Ohkuma et al., 1998; Dacks \& Redfield, 1998) that allow phylogenetic analysis of 25 identified parabasalid taxa.

\section{SALIENT POINTS IN THE MOLECULAR PHYLOGENY OF PARABASALIDS BASED ON SSU RRNA SEQUENCES}

$\Gamma$ $\mathrm{n}$ this review, we analyzed a broad phylogeny including all parabasalid sequences available in the data bases to date. Parabasalid sequences were aligned with a set of eukaryotic sequences, and phylogenetic inferences were restricted to sites that could 
be unambiguously aligned according to conservation of primary and secondary structures. The SSU rRNA sequences of Oryza sativa, Oxytricha granulifera, Toxoplasma gondii, Diaphonoeca grandis and Achlya bisexualis were used as outgroups for rooting the parabasalid tree. This data set included 1,403 positions which we analyzed with distance matrix, maximum parsimony and maximum-likelihood (ML) methods.

\section{ANALYSIS OF THE SSU RDNA SEQUENCES FROM PARABASALIDS}

The amplification of the SSU rDNA coding regions of parabasalid species produced a DNA fragment of around $1500 \mathrm{bp}$ in length with a $\mathrm{G}+\mathrm{C}$ content of 46$50 \%$ except for Dientamoeba fragilis which contains $1,600 \mathrm{bp}$ in length and had a $\mathrm{G}+\mathrm{C}$ content of $38 \%$ (Silberman et al., 1996). The lower $\mathrm{G}+\mathrm{C}$ content of the Dientamoeba fragilis SSU rRNA is accounted for by extended $\mathrm{A}+\mathrm{T}$ rich hypervariable regions. The nucleotide chain length of parabasalid SSU rRNAs are several hundred residues shorter than the 1,800 positions typical in other eukaryotes and in correlation with previous data on ribosomes (Champney et al., 1992). Ribosomes from these microorganisms are atypical of eukaryotic cells and have several characteristics in common with those of prokaryotics. They exhibit a sedimentation coefficient of 705 which dissociated into subunits of $50 \mathrm{~S}$ and 30S. Moreover, ribosomal RNAs from parabasalids exhibit the molecular sizes typical of $23 \mathrm{~S}$ and $16 \mathrm{~S}$ prokaryotic ribosomal RNAs (Noller, 1984; Gunderson \& Sogin, 1986). The small size of the ribosomal RNAs may be consistent with the postulated early evolutionary divergence of the parabasalids (Champney et al., 1992).

\section{BRANCHING PATTERN WITHIN THE PARABASALIDS}

In the ML tree shown in Figure 4, parabasalids form a monophyletic group as supposed by morphological characters (Brugerolle, 1976). Within the parabasalids, we identified four clades well supported by bootstrap values. In addition to these relatively robust groups, there are also several discrete lineages comprising single species.

The first clade includes all the free-living genera of the Monocercomonadidae (Monotrichomonas, Ditrichomonas and Pseudotrichomonas) and nearly all species from the subfamily Trichomonadinae (Trichomonas vaginalis, Trichomonas tenax, Tetratrichomonas gallinarum, Pentatrichomonas hominis, Trichomitus trypanoides and Pseudotrypanosoma giganteum). This large group also contains the genus Pentatrichomonoides, usually placed in its own subfamily Pentatrichomonoidinae (Brugerolle, 1976). Interestingly, Trichomitus batrachorum, previously classified in the
Trichomonadinae, does not belong to this large cluster. This grouping of the free-living Monocercomonadidae with the Trichomonadinae is in correlation with relationships inferred from morphological data. The Trichomonadinae and the free-living species share common morphological characters such as an undulating membrane. The undulating membrane is a ribbon-like expansion containing a dense fibre, not found in members of the subfamily Tritrichomonadinae, represented by Tritrichomonas foetus in our analysis. Among the free living monocercomonads, Pseudotrichomonas is the most basal of the three taxa. The positioning of Pseudotrichomas is consistent with a stepwise reduction of flagellar number. Indeed, Monotrichomonas possesses two flagella whereas three and four flagella occur in Ditrichomonas and Pseudotrichomonas, respectively (Farmer, 1993; Simpson et al., unpublished observations). Within the Trichomonadinae, Pentatrichomonas exhibits the most basal position. One characteristic of this taxa is the possession of five anterior flagella (Honigberg et al., 1968), whereas the other Trichomonadinae species have four anterior flagella. Pentatrichomonoides also possesses five anterior flagella, but the arrangement of the basal bodies is different to that of Pentatrichomonas (Brugerolle et al., 1994). According to our data, the presence of five anterior flagella is probably an apomorphic state in the Trichomonadinae.

A second clade unites the Devescovinidae and the Calonymphidae, that is consistent with earlier taxonomic divisions and evolutionary schemes based on light- and electron-microscopic studies (Honigberg, 1963; Brugerolle, 1976). It also includes the unidentified Porotermes adamsoni gut symbiont sequence as previously shown (Keeling et al., 1998). A third clade contains the species Trichomitus batrachorum strains R105 and BUB and Hypotrichomonas acosta. Unlike Trichomitus which possesses a developed costa, Hypotrichomonas is acostate but possesses a poorly developed undulating membrane. Several authors (Samuels, 1959; Honigberg, 1963; Mattern et al., 1969; Brugerolle, 1971) have already proposed a common evolutionary history for these two taxa on the basis of ultrastructural data that is in agreement with our molecular analysis. The fourth clade consists of the three identified hypermastigid species from the genus Trichonympha.

The phylogenetic position of the trichomonads Tritrichomonas foetus, Monocercomonas sp. and Dientamoeba fragilis remained unresolved, as observed in previous phylogenetic analyses using SSU rDNA sequences (Dacks \& Redfield, 1998; Edgcomb et al., 1998; Keeling et al., 1998). With low bootstrap support, Tritrichomonas and Dientamoeba grouped together in our tree, while Monocercomonas sp. emerged independently. Nevertheless, the grouping of Tritricho- 


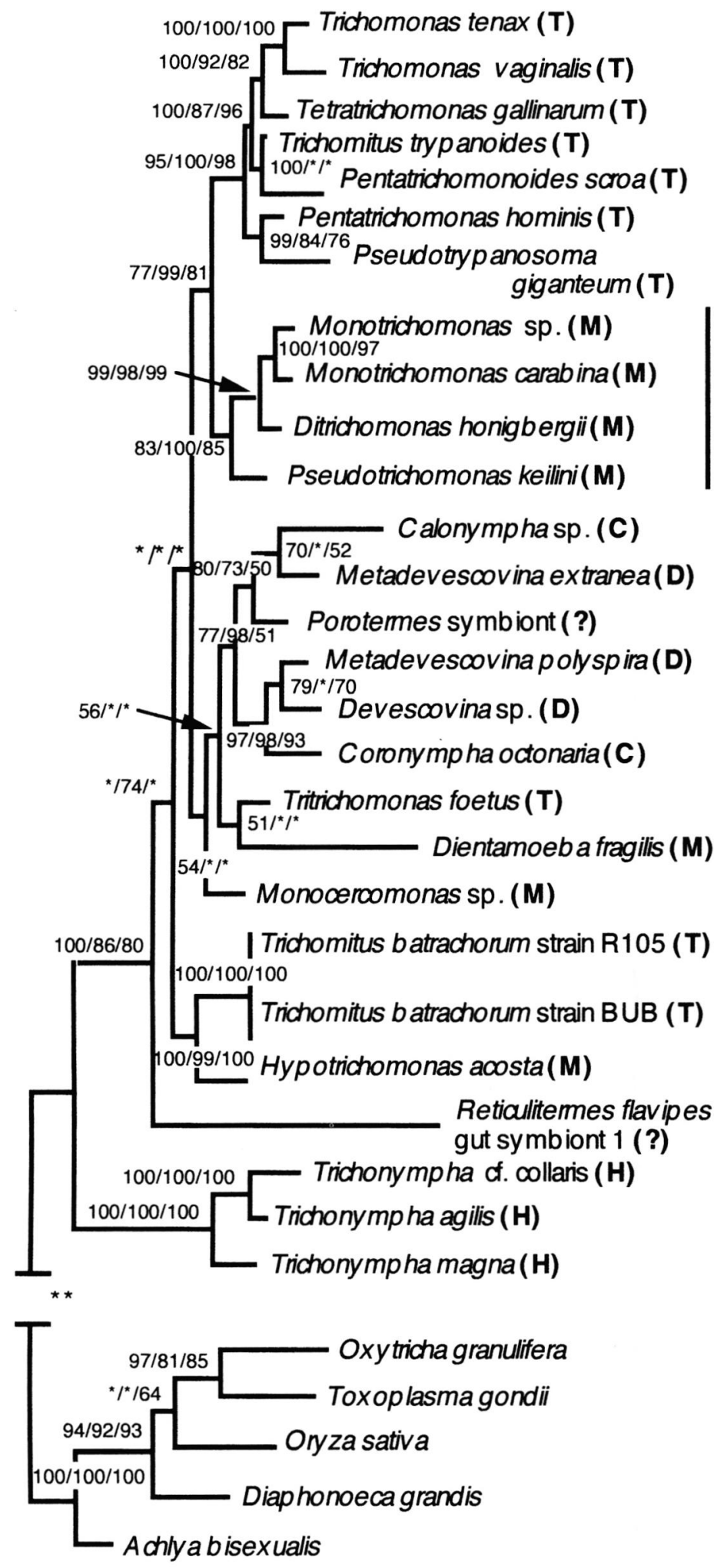

FREE-LIVING

0.100 expected substitutions/site

* Bootstrap less than $\mathbf{5 0 \%}$ Maximum likelihood/ Distance/Parsimony

** Branch length of 1.7

Fig. 4. - Rooted phylogenetic tree of parabasalids based on the comparison of SSU rDNA sequences. The tree was constructed using the maximum likelihood method (ML) using PAUP* version 4.0.0d63. After parameter optimization, heuristic searches under ML found the best tree with $\operatorname{lnL}=-10920.34123$. Bootstrap proportions are given as percentages near the individual nodes. Bootstrap values are computed by three different tree reconstruction methods: maximum likelihood (102 replicates), distance (1,000 replicates) and parsimony (1,000 replicates). Asterisks designate nodes with bootstrap values below $50 \%$. The horizontal length of each branch is proportional to the estimated number of substitutions whereas the vertical length of each branch is arbitrary. The systematic assignment of each parabasalid taxon is indicated as established from morphological data: $(\mathrm{M})=$ Monocercomonadidae; $(\mathrm{T})=$ Trichomonadidae; $(\mathrm{D})=$ Devescovinidae; $(\mathrm{C})=$ Calonymphidae; $(\mathrm{H})$ = Hypermastigid; $(?)=$ Unidentified. 
monas with Monocercomonas sp. is found in phylogenies based on LSU rRNA (Viscogliosi et al., 1993), FeSOD (Viscogliosi et al., 1996), GAPDH (Viscogliosi \& Müller, 1998) and fumarase (Gerbod et al., unpublished data) sequences, suggesting that these two genera may be related. Interestingly, we note that Tritrichomonas and Monocercomonas sp. emerged as sister groups of the clade that includes Devescovinidae. The Devescovinidae share characters in common with Tritrichomonas and Monocercomonas sp. from which they probably evolved (Honigberg, 1963; Brugerolle, 1976).

In summary, the principle clades identified in our molecular phylogeny, Trichomonadinae, Calonymphidae, Devescovinidae and the free-living Monocercomonadidae are consistent with classifications based on morphological analysis, although the relative branching order of these groups and the phylogenetic positions of some taxa remain unresolved. This congruence between morphological and molecular data is only observed at some intermediate and higher taxonomic levels. This partial consistency supports the validity of the molecular approach and confirms the quality of some, but not all, of the morphological characters that were used. However, major surprises are also observed in the molecular analysis that provide an unexpected evolutionary scenario in parabasalids.

\section{MONOCERCOMONADIDAE AND TRICHOMONADIDAE DO NOT FORM MONOPHYLETIC GROUPS}

Molecular phylogenetic approaches can be used to test taxonomic relationships originally inferred from morphological data. A taxon is considered to be natural when it appears on phylogenetic trees as a monophyletic clade. In our phylogenetic analysis neither the Monocercomonadidae or the Trichomonadidae are monophyletic (sensu Hennig), at least one of the two being polyphyletic. As stated above, the principle taxonomic character separating these two families is the presence/absence of a costa. This fiber is present in Trichomonadidae whereas it is absent in the Monocercomonadidae. Within the Trichomonadidae, members of the Tritrichomonadinae such as Tritrichomonas foetus possess C1-type costa while most members of the Trichomonadinae such as Trichomonas vaginalis possess C-type costa. Only the Trichomonadinae Trichomitus batrachorum exhibits a C1-type costa. The C-type costa found is usually presumed to have derived from the "primitive" C1-type costa because of its higher ultrastructural complexity (Viscogliosi \& Brugerolle, 1994). This is supported by the earlier emergence of Tritrichomonas foetus and Trichomitus batrachorum in our phylogenetic tree. According to biochemical, immunological and preliminary molecular data (Viscogliosi \& Brugerolle, 1994; Viscogliosi \& Delgado-Vis- cogliosi, 1996), costa proteins composing the C- and C1-type costae probably belong to the same protein family. Thus the polyphyly of the Trichomonadidae which would require multiple origins for the costa, is unlikely and we suggest the alternative of polyphyly of the Monocercomonadidae. Since all Monocercomonadidae studied to date are sister groups of taxa possessing a costa (Trichomonadidae), it appears that Monocercomonadidae are probably secondarily acostate and that the apparent simplicity of their cytoskeleton was misleading both as a primitive character and as a significant taxonomic criterion. Similarly, we also note in our analysis that both Devescovinidae and Calonymphidae do not compose monophyletic groups

\section{EARLY EMERGENCE OF HYPERMASTIGIDS}

The early emergence of the hypermastigids, the parabasalids with a hyperdeveloped cytoskeleton, classically considered to be a late-evolving lineage, causes us to reconsider the polarization of characters in comparative morphological analyses. In our SSU rDNA phylogeny, the hypermastigids of the genus Trichonympha represent the deepest branch, followed by the Reticulitermes flavipes gut symbiont 1 . This root (or the most primitive taxon of the group) is well supported by bootstrap resampling. Hypermastigids have traditionally been considered to have arisen from the Devescovinidae (Brugerolle, 1976). However, they are not specifically related to this family in our analysis. The identification of the unknown parabasalid sequence Reticulitermes flavipes gut symbiont 1 remains unresolved although the hypermastigids Spirotrichonympha, Microjoenia or Holomastigotes are the most likely sources of this sequence (Yamin, 1979). In previously published analyses (Gunderson et al., 1995 ; Dacks \& Redfield, 1998; Silberman et al., 1996), the earliest branch of the parabasalids is the unidentified symbiont 1 from Reticulitermes flavipes, which is followed by Trichonympha. Keeling et al. (1998) have found that the root of the parabasalid group was difficult to discern accurately but proposed a root somewhere among the branches leading to Trichonympha and unidentified putative hypermastigids. Although the exact branching pattern for the basal lineages is not clear yet, all are hypermastigids or putative hypermastigids. In sum, the molecular data indicate that the cytoskeletal complexity of parabasalids, while useful as a taxonomic trait, is not a reliable phylogenetic indicator, and that their traditional polarization, from "simple" to "complex" must be turned almost upsidedown. A parallel can be drawn between these results and those obtained in other groups of protists such as the ciliates (Baroin-Tourancheau et al., 1992), which suggest that a complex oral apparatus may be a ple- 
siomorphic state. Complex characters may not always be apomorphic states.

\section{FREE-LIVING MONOCERCOMONADS ARE DESCENDED FROM ENDOBIOTIC ANCESTORS}

Ditrichomonas, Pseudotrichomonas and Monotrichomonas are free-living organisms isolated from sediment samples. These free-living organisms were logically thought to antedate those of a parasitic or symbiotic habit. Until now, phylogenetic analyses of parasitic protist clades such as the diplomonads (Brugerolle, 1975b) appear to corroborate the generalization of the irreversibility of parasitism. Brugerolle \& Taylor (1977) and Vickerman (1989) assume the free-living status to be plesiomorphic for the diplomonads, in accordance with the notion that parasitism cannot be reversed. However Siddall et al. (1993), on the basis of phylogenetic trees inferred from ultrastructural characters, propose that parasitism is plesiomorphic for this group and invoke a reversal from parasitism to a free-living strategy in descendants to explain the observed patterns. In our SSU rDNA phylogeny, the free-living parabasalid clade emerges as the sister group of the Trichomonadinae with high bootstrap support. In showing the free-living species to be positioned "high" in the parabasalid tree, it strongly supports the hypothesis that they are descended from endobiotic ancestors and, thus, appear to be secondarily free-living. Moreover, the monophyly of the free-living parabasalids invokes a single reversal event from parasitism to a free-living strategy. It also means that some parabasalids are able to pursue a free-living mode in microaerobic sediments without mitochondria and that primitively free-living parabasalids have not been found yet.

\section{POLYPHYLY OF THE GENUS TRICHOMITUS}

The genus Trichomitus, and particularly the type species Trichomitus batrachorum (frog endosymbiont), has been extensively studied and characterized by light and electron microscopy (Brugerolle, 1971 ; Honigberg et al., 1972). The strains R105 and BUB were positively identified as different strains of Trichomitus batrachorum. The SSU rDNA sequences of these two strains only differ in two positions ( 527 and 1332 bases from the 5' end) and they group consistently with the monocercomonad Hypotrichomonas acosta as already predicted (Samuels, 1959). This phylogenetic positon differs markedly from that of Trichomitus trypanoides (termite-gut symbiont) which is the sister group of another termite-dwelling species, Pentatrichomonoides scroa. From this data it is clear that Trichomitus batrachorum and Trichomitus trypanoides are non-congeneric. Taking these molecular data into consideration, it is possible to repeat a comparative morphological analysis of these two species and find several ultrastructural differences that appeared as minor features. For instance, we note differences between these taxa in the length of the costa, the form of the parabasal body and the possible presence of a structure associated with the costa, the comb (Brugerolle, 1971; Honigberg et al., 1972; Boykin et al., 1986). These differences reflect polyphyly of the genus Trichomitus, and therefore it would be logical to consider such characters in further comparative structural analyses. Interestingly we note that the devescovinid genus Metadevescovina is also polyphyletic in our SSU rDNA analysis but the distance observed between the two Metadevescovina species is shorter than that calculated between the two Trichomitus species.

Trichomitus trypanoides was originally classified in the genus Trichomonas (Duboscq \& Grassé, 1924) but authors around that time usually assigned all parabasalids with an undulating membrane to the genus Trichomonas. Moreover, Trichomitus trypanoides differs from Trichomonas by several ultrastructural characters and, thus, it should be classified as a new genus of Trichomonadinae. Pending revision of the genus Trichomitus, we refer to the genus Trichomitus as encompassing members more closely related to Trichomitus batrachorum (the type species). Finally it must also be indicated that Trichomitus batrachorum has been previously classified in the Trichomonadinae, in conflict with our phylogenetic tree. In fact Trichomitus batrachorum exhibits characters from both Trichomonadinae (undulating membrane) and Tritrichomonadinae (C1-type costa). The early emergence of Trichomitus batrachorum at the base of the Trichomonadinae-Tritrichomonadinae dichotomy is therefore not really surprising and is in agreement with previous molecular phylogenies based on LSU rRNA (Viscogliosi et al., 1993) and GAPDH sequences (Viscogliosi \& Müller, 1998), emphasizing its crucial evolutionary position among the Trichomonadidae.

\section{IS THERE CORRELATION BETWEEN THE PHYLOGENY OF PARABASALIDS AND THEIR HOSTS?}

We also studied the phylogenetic position of parabasalids isolated from various hosts in an attempt to gain further insights into the evolution of parasitism among these protists. Our analysis provides no evidence for a long-term co-evolution of parabasalids and their hosts, either vertebrate or invertebrate. These observations suggest that evolution of parabasalids was accompanied by multiple changes of hosts and habitats. For instance, the early emergence of Tritrichomonas foetus and Dientamoeba fragilis (mammalian parasites), together with the late emergence of the insect gut inhabitants Trichomitus trypanoides, Pentatrichomonoides scroa and Pseudotrypanosoma giganteum in our SSU rDNA phylogeny, is intriguing evi- 
dence against the theoretical co-evolution of these organisms and their animal hosts as already suggested by Silberman et al. (1996). However our data cannot exclude the possibility of a limited (short-term) co-evolution of hosts and parasites. Within the monophyletic clade of the Trichomonadinae, which includes mammalian (Trichomonas vaginalis, Trichomonas tenax and Pentatrichomonas bominis), bird (Tetratrichomonas gallinarum) and termite hosts (Trichomitus trypanoides, Pentatrichomonoides scroa and Pseudotrypanosoma giganteum), the parasitic parabasalid lineages of this group emerge in an order reflecting the evolutionary history of their hosts, with the exception of Pentatrichomonas hominis.

\section{CONCLUSION}

Ther $\mathrm{n}$ recent molecular studies, there has been a tendency to believe that evolutionary reconstructions have resolved all major questions regarding parabasalid evolution. In this review we show that some uncertainties remain in the molecular phylogeny of parabasalids, such as the position of several taxa and the relative branching order of the major groups of parabasalids. The inclusion of several as yet untouched taxa in molecular phylogenetic analyses, particularly termite symbionts, could help to address these issues. Molecular phylogenies as inferred from SSU rRNA sequences are providing some important and sometimes unexpected insights into the evolution of the parabasalid group. Despite some encouraging congruencies, the molecular data conflict with the established systematics based on a limited number of morphological characters and, broadly, a simple-tocomplex polarisation of evolution. One of the best examples of these discrepancies is the probable polyphyly of the Monocercomonadidae. Molecular approaches allow us to follow the elaboration of the cytoskeleton in the parabasalid lineage, and in some taxa, to shed light on undetected secondary losses of cytoskeletal structures or to propose an increased "weight" for some ultrastructural characters in further analyses.

It is true that many systematists have emphasized the conflicts and deemphasized the concordance between inferences based on molecular data and those based on morphology, although each approach has distinct virtues and pitfalls. However studies that incorporate both molecular and morphological data will provide much better descriptions and interpretations of biological diversity than those that focus on just one approach. The necessary revision of the parabasalid taxonomy should take into account both molecular and morphological data in the near future.

\section{REFERENCES}

Baroin-Tourancheau A., Delgado P., Perasso R. \& Adoutte A. A broad molecular phylogeny of ciliates: identification of major evolutionary trends and radiations within the phylum. Proceedings of the National Academy of Sciences USA, 1992, 89, 9764-9768.

Berchtold M. \& König H. Phylogenetic position of the two uncultivated trichomonads Pentatrichomonoides scroa Kirby and Metadevescovina extranea Kirby from the hindgut of the termite Mastotermes darwiniensis Froggatt. Systematic and Applied Microbiology, 1995, 18, 567-573.

Berchtold M., Breunig A. \& König H. Culture and phylogenetic characterization of Trichomitus trypanoides Duboscq \& Grassè 1924, n. comb: a trichomonad flagellate isolated from the hindgut of the termite Reticulitermes santonensis Feytaud. Journal of Eukaryotic Microbiology, 1995, 42, 388391.

Boykin M.S., Stockert L., Buhse H.E. \& Smith-Somerville H.E. Trichomitus trypanoides (Trichomonadida) from the termite Reticulotermes flavipes. II. Fine structure and identification of the cloned flagellate. Transactions of the American Microscopical Society, 1986, 105, 223-238.

BREZNAK J.A. Intestinal microbiota of termites and other xylophagous insects. Annual Review of Microbiology, 1982, 36, 323-343.

Brugerolle G. Ultrastructure du genre Trichomitus Swezy 1915, Zooflagellata, Trichomonadida. Protistologica, 1971, 7, 171-176.

Brugerolle G. Étude de la cryptopleuromitose et de la morphogénèse de division chez Trichomonas vaginalis et chez plusieurs genres de Trichomonadines primitives. Protistologica, 1975a, 11, 457-468.

Brugerolle G. Contribution à l'étude phylétique des diplozoaires (Zoomastigophorea, Diplozoa, Dangeard, 1910). VI. Caractères généraux des diplozoaires. Protistologica, 1975b, 11, 111-118.

Brugerolle G. Cytologie ultrastructurale, systématique et évolution des Trichomonadida. Annales de la Station Biologique de Besse-en-Chandesse, 1976, 10, 1-90.

Brugerolle G. \& Taylor F.J.R. Taxonomy, cytology and evolution of the Mastigophora, in: Proceedings of the Fifth International Congress of Protozoology, 1977, 14-28.

Brugerolle G., Breunig A. \& KÖNIG H. Ultrastructural study of Pentatrichomonoides sp., a trichomonad flagellate from Mastotermes darwiniensis. European Journal of Protistology, 1994, 30, 372-378.

But E.T.N., Bradley P.J. \& Johnson P.J. A common evolutionary origin for mitochondria and hydrogenosomes. Proceedings of the National Academy of Sciences USA, 1996, 93, 9651-9656.

Cavalier-Smith T. Kingdom Protozoa and its 18 phyla. Microbiological Reviews, 1993, 57, 953-994.

Champney W.S., Chittum H.S. \& Samuels R. Ribosomes from trichomonad protozoa have prokaryotic characteristics. International Journal of Biochemistry, 1992, 24, 11251133. 
Coruss J.O. The kingdom Protista and its 45 phyla. BioSystems, 1984, 17, 87-126.

Dacks J.B. \& Redfield R.J. Phylogenetic placement of Trichonympha. Journal of Eukaryotic Microbiology, 1998, 45, 445-447.

Delgado-Viscogliosi P., Viscogliosi E., Gerbod D., Kulda J., Sogin M.L. \& Edgcomb V.P. A comprehensive molecular phylogeny of parabasalids based on small subunit rRNA sequences : an unexpected evolutionary scenario. Journal of Eukaryotic Microbiology, 1999, in press.

DuboscQ O. \& Grassé P-P. Notes sur les protistes parasites des termites de France. I. Trichomonas trypanoides, n. sp. Comptes-rendus des Séances de la Société de Biologie, Paris, 1924, 90, 547-550.

DYer B.D. Phylum Zoomastigina Class Parabasalia, in: Handbook of Protoctista. Margulis L., Corliss J.O., Melkonian M. \& Chapman D.J. (eds), Jones \& Bartlett, Boston, 1989, 252-258

Edgcomb V.P., Viscogliosi E., Simpson A.G.B., Delgado-VisCogliosi P., Roger A.J. \& Sogin M.L. New insights into the phylogeny of trichomonads inferred from small subunit rRNA sequences. Protist, 1998, 149, 359-366.

FARMER M.A. Ultrastructure of Ditrichomonas honigbergii n. g., n. sp. (Parabasalia) and its relationship to amitochondrial protists. Journal of Eukaryotic Microbiology, 1993, 40, 619626.

Fukura K., Yamamoto A., Hashimoto T. \& Goto N. Nucleotide sequence of the SrRNA gene and phylogenetic analysis of Trichomonas tenax. Microbiology and Immunology, 1996, 40, 183-188.

Germot A., Philippe H. \& Le Guyader H. Presence of a mitochondrial-type $70-\mathrm{kDa}$ heat shock protein in Trichomonas vaginalis suggests a very early mitochondrial endosymbiosis in eukaryotes. Proceedings of the National Academy of Sciences USA, 1996, 93, 14614-14617.

Germot A., Philippe H. \& Le Guyader H. Loss of mitochondria in microsporidia: evidence from a mitochondrial-type HSP-70 in Nosema locustae. Molecular and Biochemical Parasitology, 1997, 87, 159-168.

GraIN J. The cytoskeleton in protists: nature, structure and function. International Review of Cytology, 1986, 104, 153249.

Graves A. \& Gardner W.A. Pathogenicity of Trichomonas vaginalis. Clinical Obstetrics and Gynecology, 1993, 36, 145-152.

Grosovsky B.D.D. \& Margulis L. Termite microbial communities, in: Experimental Microbial Ecology. Burns R.G. \& Slater J.H. (eds), Oxford, Blackwell Scientific, 1982, 519532.

Gunderson J.H. \& SogIn M.L. Length variations in eukaryotic rRNAs: small subunit rRNAs from the protists Acanthamoeba castellani and Euglena gracilis. Gene, 1986, 44, 6370

Gunderson J., Hinkle G., Leipe D., Morrison H.G., Stickel S.K., Odelson D.A., Breznak J.A., Nerad T.A., Müller M. \& SoGIN M.L. Phylogeny of trichomonads inferred from smallsubunit rRNA sequences. Journal of Eukaryotic Microbiology, 1995, 42, 411-415.
Heine P. \& McGregor J.A. Trichomonas vaginalis: a reemerging pathogen. Clinical Obstetrics and Gynecology, 1993, 36, 137-144.

Hirt R.P., Healy B., Vossbrinck C.R., Canning E.U. \& Embley T.M. A mitochondrial HSP70 orthologue in Vairimorpha necatrix: molecular evidence that microsporidia once contained mitochondria. Current Biology, 1997, 7, 995-998.

Hollande A. \& Carruette-Valentin J. Les atractophores, l'induction du fuseau et la division cellulaire chez les Hypermastigines, étude infrastructurale et révision systématique des Trichonymphines et des Spirotrichonymphines. Protistologica, 1971, 7, 5-100.

Honigberg B.M. Evolutionary and systematic relationships in the flagellate order Trichomonadida Kirby. Journal of Protozoology, 1963, 10, 20-63.

Honigberg B.M., Mattern C.F.T. \& Daniel W.A. Structure of Pentatrichomonas hominis as revealed by electron microscopy. Journal of Protozoology, 1968, 15, 419-430.

Honigberg B.M., Daniel W.A. \& Mattern C.F.T. Fine structure of Trichomitus batrachorum (Perty). Journal of Protozoology, 1972, 19, 446-453.

Honigberg B.M. Trichomonads of importance in human medecine, in: Parasitic Protozoa. Kreier J.P. (ed), Academic Press, New York, 1978, vol. II, 275-454.

Honigberg B.M. \& Brugerolle G. Structure, in: Trichomonads parasitic in humans. Honigberg B.M. (ed), Springer-Verlag, New York, 1990, 5-35.

Keeling P.J., Poulson N. \& McFadden G.I. Phylogenetic diversity of parabasalian symbionts from termites, including the phylogenetic position of Pseudotrypanosoma and Trichonympha. Journal of Eukaryotic Microbiology, 1998, 45, 643650.

KIrBy B. Devescovinid flagellates of termites. I. The genus Devescovina. University of California Publications in Zoo$\log$, 1941, 45, 1-92.

Kulda J., NohynKova E. \& LudviK J. Basic structure and function of the trichomonad cell. Acta Universitatis CarolinaeBiologica, 1986, 30, 181-210.

LEE J.J. Order 5. Trichomonadida, in: Illustrated Guide to the Protozoa. Lee J.J., Hutner S.H. \& Bovee E.C. (eds), Allen Press, Lawrence, Kansas, 1985, 119-127.

Leipe D.D., Gunderson J.H., Nerad T.A. \& Sogin M.L. Small subunit ribosomal $\mathrm{RNA}^{+}$of Hexamita inflata and the quest for the first branch in the eukaryotic tree. Molecular and Biochemical Parasitology, 1993, 59, 41-48.

Levine N.D., Corliss J.O., Cox F.E., Deroux G., Grain J., HonigBerg B.M., Leedale G.F., Loeblich A.R.D., Lom J., Lynn D., Merinfeld E.G., Page F.C., Poljansky G., Sprague V., Vavra J. \& Wallace F.G. A newly revised classification of the protozoa. Journal of Protozoology, 1980, 27, 37-58.

Mattern C.F.T., Daniel W.A. \& Honigberg B.M. Structure of Hypotrichomonas acosta (Moskowitz) (Monocercomonadidae, Trichomonadida) as revealed by electron microscopy. Journal of Protozoology, 1969, 16, 668-685.

Medin L., Elwood H.J., Stickel S. \& Sogin M.L. The characterization of enzymatically amplified eukaryotic 16S-like rRNA coding regions. Gene, 1988, 71, 491-499. 
Noller H.F. Structure of ribosomal RNA. Annual Review of Biochemistry, 1984, 53, 119-162.

Ohkuma M., Оhtoko K., Grunau C., Moriya S. \& Kudo T. Phylogenetic identification of the symbiotic hypermastigote Trichonympha agilis in the hindgut of the termite Reticulitermes speratus based on small-subunit rRNA sequence. Journal of Eukaryotic Microbiology, 1998, 45, 439-444.

Olsen G.J. \& Woese C.R. Ribosomal RNA: a key to phylogeny. FASEB Journal, 1993, 7, 113-123.

Pace N.R., Olsen G.J. \& Woese C.R. Ribosomal RNA phylogeny and the primary lines of evolutionary descent. Cell, 1986, 45, 325-326.

PeCKa Z., NoHYnKova E. \& Kulda J. Ultrastructure of Cochlosoma anatis Kotlan, 1923 and taxonomic position of the family Cochlosomatidae (Parabasala: Trichomonadida). European Journal of Protistology, 1996, 32, 190-201.

Peyretaillade E., Broussole V., Peyret P., Metenier G., Gouy M. \& Vivares C.P. Microsporidia, amitochondriate protists, possess a $70-\mathrm{kDa}$ heat shock protein gene of mitochondrial origin. Molecular Biology and Evolution, 1998, 15, 683-689.

Philippe H. \& Adoutte A. How reliable is our current view of eukaryotic phylogeny?, in: Protistological Actualities, Proceedings of the Second European Congress of Protistology. Brugerolle G. \& Mignot J.P. (eds), 1995, 17-33.

Roger A.J., Clark C.G. \& Doolittle W.F. A possible mitochondrial gene in the early-branching amitochondriate protist Trichomonas vaginalis. Proceedings of the National Academy of Sciences USA, 1996, 93, 14618-14622.

Roger A.J., Svärd S.G., Tovar J., Clark C.G., Smith M.W., Gillin F.D. \& Sogin M.L. A mitochondrial-like chaperonin 60 gene in Giardia lamblia: Evidence that diplomonads once harbored an endosymbiony related to the progenitor of mitochondria. Proceedings of the National Academy of Sciences USA, 1998, 95, 229-234.

SAMUELS R. Studies of Tritrichomonas batrachorum. 3. Abnormal mitosis and morphogenesis. Transactions of the American Microscopical Society, 1959, 78, 49-65.

Siddall M.E., Brooks D.R. \& Desser S.S. Phylogeny and the reversibility of parasitism. Evolution, 1993, 47, 308-313.

Silberman J.D., Clark C.G. \& Sogin M.L. Dientamoeba fragilis shares a recent common evolutionary history with the trichomonads. Molecular and Biochemical Parasitology, 1996, 76, 311-314.

Sogin M.L. Early evolution and the origin of eukaryotes. Current Opinion in Genetics and Development, 1991, 1, 457463.

SORVILLO F. \& KeRndt P. Trichomonas vaginalis and amplification of HIV-1 transmission. The Lancet, 1998, 351, 213214.

TAYLOR F.J.R. Problems in the development of an explicit hypothetical phylogeny of the lower eucaryotes. BioSystems, 1978, 10, 67-89.

Van Keulen H., Gutell R.R., Gates M.A., Campbell S.R., Erlandsen S.L., Jarroll E.L., Kulda J. \& Meyer E.A. Unique phylogenetic position of Diplomonadida based on the complete small subunit ribosomal RNA sequence of Giardia ardeae, G. muris, G. duodenalis and Hexamita sp. FASEB Journal, 1993, 7, 223-231.
Vickerman K. Phylum Zoomastigina Class Diplomonadida, in: Handbook of Protoctista. Margulis L., Corliss J.O., Melkonian M. \& Chapman D.J. (eds), Jones \& Bartlett, Boston, 1989, 200-210.

Viscogliosi E., Philippe H., Baroin A., Perasso R. \& BrugeROLLE G. Phylogeny of trichomonads based on partial sequences of large subunit rRNA and on cladistic analysis of morphological data. Journal of Eukaryotic Microbiology, 1993, 40, 411-421.

Viscogliosi E. \& Brugerolle G. Striated fibers in trichomonads: costa proteins represent a new class of proteins forming striated roots in protists. Cell Motility and the Cytoskeleton, 1994, 29, 82-93.

Viscogliosi E. \& Delgado-Viscogliosi P. Cytoskeleton, division and evolution in a primitive group of protists, the trichomonads. Année Biologique, 1996, 35, 146-162.

Viscogliosi E., Durieux I., Delgado-Viscogliosi P., Bayle D. \& Drve D. Phylogenetic implication of iron-containing superoxide dismutase genes from trichomonad species. Molecular and Biochemical Parasitology, 1996, 80, 209214.

Viscogliosi E. \& Müller M. Phylogenetic relationships of the glycolytic enzyme, glyceraldehyde-3-phosphate dehydrogenase, from parabasalid flagellates. Journal of Molecular Evolution, 1998, 47, 190-199.

WOESE C.R. Bacterial evolution. Microbiological Reviews, 1987, 51, 221-271.

YAmin M.A. Flagellates of the orders Trichomonadida Kirby, Oxymonadida Grassé, and Hypermastigida Grassi \& Foà reported from lower termites (Isoptera families Mastotermitidae, Kalotermitidae, Hodotermitidae, Termopsidae, Rhinotermitidae, and Serritermitidae) and from the woodfeeding roach Cryptocercus (Dictyoptera: Cryptocercidae). Sociobiology, 1979, 4, 5-119.

Yule A., SkIRrow S.Z. \& Bondurant R.H. Bovine Trichomoniasis. Parasitology Today, 1989, 5, 373-377.

Zuckerkandl E. \& PAuling L. Molecules as documents of evolutionary history. Journal of Theoretical Biology, 1965, 8, $357-366$

Reçu le 6 juillet 1999

Accepté le 22 octobre 1999 